\title{
Cytotaxonomic Studies on South Indian Loranthaceae
}

\author{
T. A. Soman and K. Ramachandran \\ Department of Botany, University of Kerala, Trivandrum, India
}

Accepted July 18, 1986

Loranthaceae, chiefly a tropical family, extend into the temperate zones of both hemispheres. They include parasitic herbs, shrubs and rarely trees. There have been many nomenclatural changes and the taxonomy of the family is somewhat confusing. De Candolle (1830) divided the family into two groups, on the basis of the presence or absence of calyculus, which were treated by most systematists as subfamilies, Loranthoideae with calyculus and Viscoideae lacking calyculus. In more recent classifications, they have been raised to the status of separate families, Loranthaceae and Viscaceae respectively (Barlow 1964, Dahlgren 1977). There is also disagreement with regard to the delimitation of tribes and genera. The classification of Danser $(1929,1933)$ is now widely followed. The family has been of interest as some species cause considerable damages to timber trees and fruit crops.

Despite the large number and wide distribution of species, very little is known on the cytology of the Loranthaceae. Chromosome numbers are known in about 73 species of 24 genera mostly from meiotic studies. The most important contributions to the cytology of the family are those of Barlow $(1963,1964)$ who made extensive cytotaxonomical studies of Australian species. Chromosome numbers of a few species have been determined by Bhaumic (1971), Bir et al. (1980, 1982), Wiens (1964) and others. In the present study detailed investigations of meiosis in 14 taxa (13 species) coming under 7 genera have been made. Seven of these are new counts and in two others the numbers observed here differ from previous reports.

\section{Materials and methods}

Materials were collected from different parts of South India. Flower buds were fixed in the field in Carnoy's fluid (1:3 acetic alcohol). For staining, standard acetocarmine squash technique has been followed. Pollen fertility was determined by stainability in $1: 1$ glyceroacetocarmine. The plants were identified at the Botanical Survey of India, Coimbatore. Voucher specimens of all the plants investigated here have been deposited in the herbarium of the Department of Botany, University of Kerala, Trivandrum. The tribes and genera are arranged as in the classification of Danser (1933) and the species take an alphabetical order.

\section{Observations}

Tribe: Elytrantheae

Elytranthe B1.

The genus comprises about 10 species of which only one occurs in South India (Johri and Bhatnagar 1972). The only cytological work in this genus is a report of $n=12$ for an unidentified species by Barlow (vide Johri and Bhatnagar 1972).

1. E. parasitica (Linn.) Dans.

The samples of this species collected from different host trees in Ponmudi Hills (Kerala) showed differences in the size of flower, leaves and other vegetative characters. Both forms revealed the same haploid number of chromosomes $(n=12)$. In the larger form twelve separate 
bivalents were observed in $46 \%$ of analysed PMCs (Fig. 1). A ring of four chromosomes, indicating heterozygosity for an interchange, occurs in the rest of the PMCs (Fig. 2). Pollen grains were found to be $47 \%$ fertile.

The smaller form showed normal meiosis with 12 bivalents at diakinesis and metaphase $I$ in all the PMCs examined (Fig. 3). No multiple associations of chromosomes were observed. Pollen grains were $73 \%$ well formed.

Macrosolen B1.

The genus consists of about 40 species, of which five have been reported from India. There is a previous report of $n=12$ and $2 n=24$ in $M$. cohinchinensis (Schaeppi and Steindl 1942). In this study two species have been cytologically investigated.

2. M. capitellatus (Wight and Arn.) Dans.

Samples of plants parasitic on different tree species were collected from different localities in peninsular India. Meiotic studies showed 12 bivalents at metaphase I (Fig. 4). The bivalents showed a tendency to form sticky associations involving 2, 3 or more bivalents, in varying frequencies. The anaphase I segregation of chromosomes, however, was normal except for occasional lagging. Pollen grains were $82 \%$ well formed.

3. M. parasiticus (Linn.) Dans.

Studies of materials collected from different tree species in Ooty showed regular meiosis with 12 bivalents at metaphase I (Fig. 5). Pollen grains were 87\% well formed.

Tribe: Lorantheae.

Dendrophthoe Mart.

Out of about 47 species of the genus, 7 occur in India. Cytology of three of these has been studied here.

4. D. falcata (Linn.) Ettings (L. longiflorus Desr.)

This species is widely distributed in India. Kumar and Abraham (1942), Barlow (1963) and Bir et al. (1980) have reported $\mathrm{n}=9$ for this species. Hooker (1885) described three varieties. Cytology of two varieties has been examined in this study.

a. var. amplexifolia DC.

Meiosis was normal, showing 9 bivalents at diakinesis and metaphase I (Fig. 6). Pollen grains were found to be $96 \%$ fertile.

b. var. pubescens Hook. $\mathrm{f}$.

Samples were collected from different host trees in Kallar, near Trivandrum. Meiotic studies showed 9 bivalents at diakinesis (Fig. 7). There is a tendency for bivalents to associate into groups of varying numbers. In spite of this, the anapase segregation of chromosomes was normal and pollen grains showed good fertility $(80 \%)$.

5. D. memecylifolia (Wight and Arn.) Dans.

It occurs parasitic on various shola trees. Meiosis was regular in all the populations, with nine bivalents at diakinesis and metaphase I (Fig. 8). Pollen grains showed $62 \%$ fertility. 6. D. neelgherrensis (Wight and Arn.) Van Tiegh. (L. neelgherrensis Wight and Arn.)

It is a stout parasitic shrub common in the Nilgiris and Pulney Hills. Meiosis was normal, showing 9 bivalents at metaphase I (Fig. 9). This confirms the report by Bir et al. (1982). Pollen grains were $90 \%$ fertile.

\section{Helicanthes Dans.}

This is probably a monotypic genus (Santapau and Henry 1972).

7. H. elastica (Desr.) Dans.

This plant is easily distinguished by its white corolla tube and whorled corolla lobes which are highly elastic. Two populations of this species collected from two different areas showed interesting differences in meiosis. The samples collected from different host trees at Trivandrum exhibited 9 distinct bivalents at metaphase I (Fig. 10). This confirms the earlier report by Bir 
et al. (1982). In addition, one or two B-chromosomes were also noticed in all the populations studied (Fig. 10). The pollen grains showed $90 \%$ fertility.
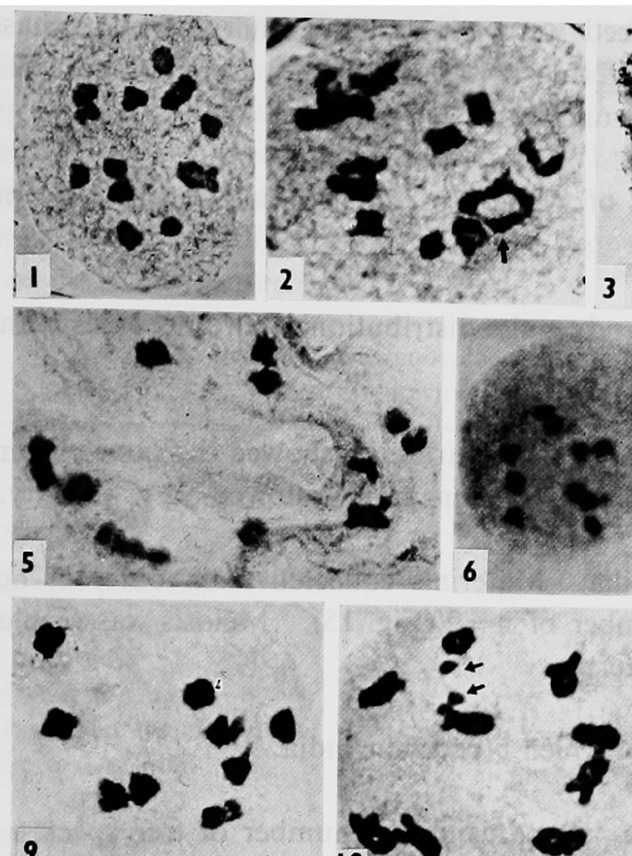

9
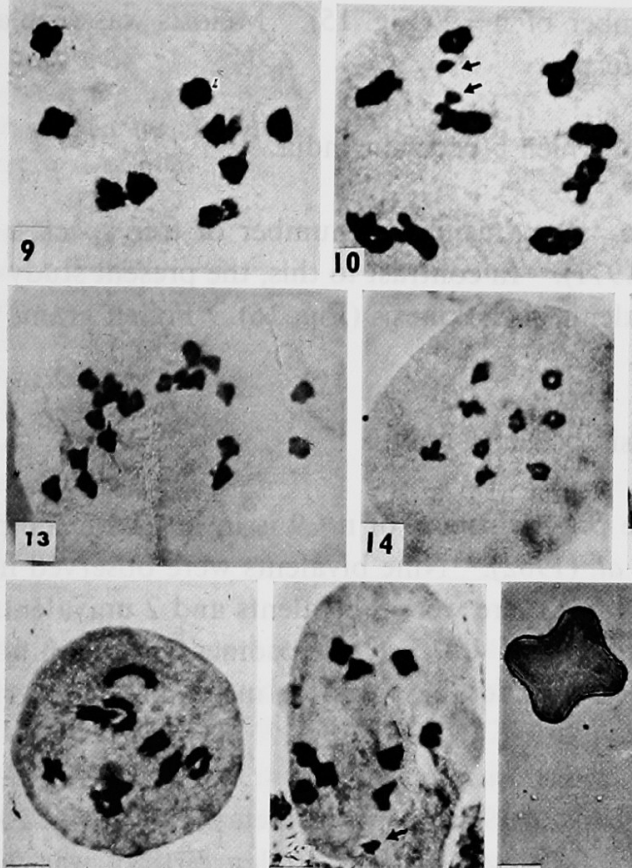

$\overline{17}$

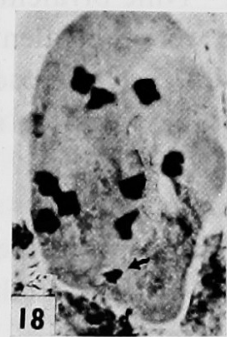

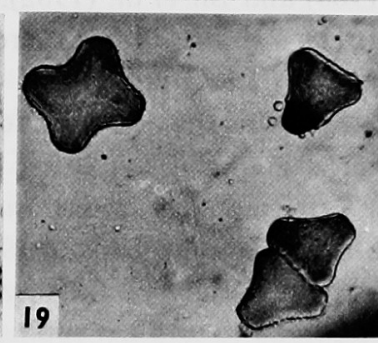
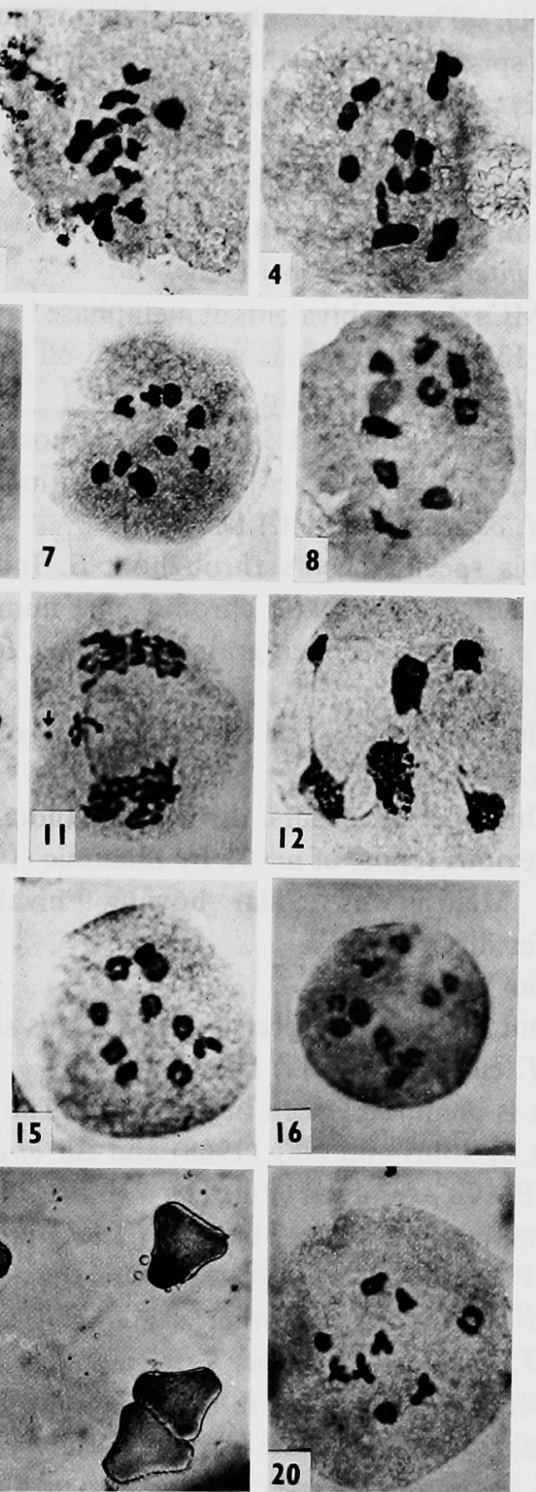

Figs. 1-20. Microphotographs of meiosis in PMCs. 1, Elytranthe parasitica, M-I, $12 \mathrm{II} . \quad \times 625$ approx. 2, E. parasitica, M-I, $10 \mathrm{II}+1 \mathrm{IV}, \times 800$ approx. 3, E. parasitica (small form), M-I, 12 II. $\times 625$ approx. 4 , Macrosolen capitellatus, M-I, 12 II, $\times 750$ approx. 5, M.parasiticus, M-I, 12 II. $\times 625$ approx. All the following photographs except No. $19(\times 375) \times 750$. 6, Dendrophthoe falcata var. amplexifolia, diakinesis, 9 II. 7, D. falcata var. pubescens, diakinesis, 9 II. 8, D. memecylifolia, diakinesis, 9 II. 9, D. neelgherrensis, M-I, 9 II. 10, Helicanthes elastica, M-I, $9 \mathrm{II}+2 \mathrm{~B}$-chromosomes. 11, $\mathrm{H}$. elastica, A-I, a bridge with fragment. 12, $\mathrm{H}$. elastica, T-II, showing 6 nuclei of varying size. 13, Helixanthera intermedia, A-I, with 9: 9 chromosomes at the poles. 14, $H$. lepidophylla, M-I, 9 II. 15, $H$. obtusata, diakinesis, 9 II. 16, Scurrula parasitica, diakinesis, 9 II. 17, Taxillus cuneatus, diakinesis, 9 II. 18, T. cuneatus, M-I, 9 II+1 B-chromosome. 19, T. cuneatus, pollen grains of different size and shape. 20, T. tomentosus, M-I, 9 II. 
The samples collected from Eranakulam also showed 9 bivalents plus one or two Bchromosomes. However, PMCs showed several chromosomal and spindle abnormalities. Chromosomal abnormalities include precocious separation of chromosomes at metaphase I, fragmentation of chromosomes, lagging, and formation of bridge with fragment at first anaphase (Fig. 11). The spindle abnormalities noticed were tripolar and multipolar anaphases and curved spindle. More than four nuclei differing in size have been found in several PMCs (Fig. 12). About $42 \%$ pollen grains were found to be sterile.

Helixanthera Lour.

The genus consists of about 50 species of which 7 occur in India. There is no previous report on the cytology of this genus.

8. H. intermedia (Wight) Dans.

PMCs showed bivalents at metaphase I and regular distribution of chromosomes at anaphase I (Fig. 13). Pollen grains were $92 \%$ well formed.

9. H. lepidophylla (Walp.) Dans.

Materials collected from different host trees in Courtallum showed the same chromosome number of $\mathrm{n}=9$ (Fig. 14) and regular meiosis. Pollen grains showed $92 \%$ fertility.

10. H. obtusata (Schult.) Dans.

This species occurs throughout S. India. Materials collected from different host tree species showed the same chromosome number of $n=9$ (Fig. 15). Meiosis was regular in all the populations. Pollen grains were $90 \%$ fertile.

Scurrula Linn.

The genus consist of over 30 species, of which 6 occur in India.

11. S. parasitica Linn.

This species occurs throughout India. It parasitizes a number of tree species. There is a previous report of $n=12$ by Bhaumic (1971). In contrast to this, the present study showed $\mathbf{n}=9$. Meiosis was regular showing 9 bivalents at diakinesis (Fig. 16). Pollen grains showed $95 \%$ fertility.

Taxillus Van Tiegh.

Out of about 60 species of this genus six occur in India.

12. T. cuneatus (Roth.) Dans.

It is commonly seen in S. India. The present report of $n=9$ is in line with the previous report by Johri and Nag (1968) and Bir et al. (1982). Nine bivalents were observed in 47 out of 60 PMCs examined (Fig. 17). In five PMCs there were 8 bivalents and 2 univalents and in the remaining 8 PMCs, 7 bivalents and 4 univalents. 0-2 B chromosomes have been noticed in a few PMCs (Fig. 18). Pollen grains showed considerable variation in size and shape (Fig. 19). About $71 \%$ appeared fertile.

13. T. tomentosus (Roth.) Van Tiegh. (L. tomentosus Heyne)

Meiosis was regular in all collections, showing 9 bivalents at metaphase I (Fig. 20). This is in agreement with the previous study of Bir et al. (1982). Pollen fertility was $92 \%$.

\section{Discussion}

Chromosome numbers of 13 species belonging to 7 genera determined in the present study are listed in Table I. Previous reports of chromosome counts in 73 species of 24 genera of the family have been given by Johri and Bhatnagar (1972). Chromosome numbers in all three tribes are available. However, chromosome numbers of too few genera and species are known for firm conclusions to be drawn regarding cytological evolution within the family.

Only two genera, Nuytsia and Loranthus were recognized by Bentham and Hooker (1883) within the Loranthoideae. Danser (1933) erected 52 genera under three tribes-Elytrantheae, 
Nuytsieae and Lorantheae. Nuytsieae consists of a single gneus Nuytsia. The two S. Indian representatives of Elytrantheae (Elytranthe and Macrosolen) investigated here showed a basic chromosome number of $\mathrm{x}=12$. The same basic number $(\mathrm{x}=12)$ has been reported previously in six other genera (Alepis, Amylotheca, Atkinsonia, Lepeostegeres, Lysiana and Peraxilla) of this tribe (Barlow 1963, Schaeppi and Steindl 1942). Basic number $\mathrm{X}=12$ seems to be characteristic to the tribe. Previous studies of 15 genera of the tribe Lorantheae have revealed varying basic numbers of $\mathrm{x}=8,9,10,11$ and 12 . However, all the five genera (Dendrophthoe, Helicanthes, Helixanthera, Scurrula and Taxillus) investigated here are based on $\mathrm{x}=9$ which is more prevalent in the tribe. This difference in basic chromosome number together with the difference in size of chromosomes seems to support the treatment of genera under 2 separate tribes as done by Danser.

Table 1. Chromosome numbers determined in this study and previous reports for the same taxa

\begin{tabular}{|c|c|c|c|c|}
\hline \multirow{3}{*}{ Name of species } & \multicolumn{4}{|c|}{ Chromosome number } \\
\hline & \multirow{2}{*}{$\frac{\text { Present study }}{\mathrm{n}}$} & \multicolumn{2}{|c|}{ Previous study } & \multirow[t]{2}{*}{ Author } \\
\hline & & $\mathrm{n}$ & $2 n$ & \\
\hline Elytranthe parasitica & 12 & & & \\
\hline Macrosolen capitellatus & 12 & & & \\
\hline M. parasiticus & 12 & & & \\
\hline Dendrophthoe falcata & & 9 & 18 & Kumar and Abraham (1942) \\
\hline (Loranthus longiflorus) & & & & Richharia and Ghosh (1952) \\
\hline var. amplexifolia & 9 & 9 & & $\begin{array}{l}\text { Barlow (1963), } \\
\text { Bir et al. }(1980)\end{array}$ \\
\hline var. pubescens & 9 & & & \\
\hline D. memecylifolia & 9 & & & \\
\hline D. neelgherrensis & 9 & 9 & & Bir et al. (1982) \\
\hline Helicanthes elastica & 9 & 9 & & Bir et al. (1982) \\
\hline Helixanthera intermedia & 9 & & & \\
\hline H. lepdophylla & 9 & & & \\
\hline H. obtusata & 9 & & & \\
\hline Scurrula parasitica & & 12 & & Bhaumic (1971) \\
\hline Taxillus cuneatus & 9 & 9 & & Bir et al. (1982) \\
\hline T. tomentosus & 9 & 9 & & Bir et al. (1982) \\
\hline
\end{tabular}

The basic number $x=12$ is constant throughout the tribes Elytrantheae and Nuytsieae, which are less specialized in morphological characters than Lorantheae, which show an aneuploid series of $\mathrm{x}=8,9,10,11$ and 12. In the Lorantheae the genera Phrygilanthus and Muellerina, which show more primitive characters, have higher basic numbers $(x=11,12)$ than the more specialized genera. The evolutionary trend, therefore, appears to have been towards dysploid reduction from $x=12$ to 8 . Polyploidy is rare in the family, and as suggested by Johri and Bhatnagar (l.c.) may be due to the "unique features of habit and reproduction". In the sub family Loranthoideae the ancestral basic number is $x=12$. In this it differs from Viscoideae in which the two tribes have a higher basic number of $x=14$ (Barlow 1963). This indicates that they had probably separate origin, and evolved along distinct lines. This lends further support to their treatment as separate families, Loranthaceae and Viscaceae, respectively.

\section{Summary}

Meiotic studies were carried out on 14 taxa representing 7 genera of the family Loranthaceae. The cytology of 8 taxa is reported for the first time. Heterozygosity for an inter- 
change was observed in $E$. parasitica. Supernumerary chromosomes were observed in $\boldsymbol{H}$. elastica and $T$. cuneatus. The difference in basic chromosome number and size of chromosomes in Elytrantheae and Lorantheae seems to convince the integrity of the two tribes. In contrast to the fixed basic number of $x=12$ in Elytrantheae and Nuytsieae, the tribe Lorantheae showed an aneuploid series of $x=8,9,10,11$ and 12 . In the tribe Lorantheae the primitive genera showed higher basic numbers compared to the more specialised genera which indicates that dysploid reduction from $x=12$ to $x=8$ occurred during evolution.

\section{Acknowledgements}

The authors are greatly indebted to Prof. (Dr.) C. A. Ninan, Head of the Department of Botany, University of Kerala for providing facilities and constant encouragements. The authors are thankful to the Botanical Survey of India, Coimbatore for the identification of plants.

\section{References}

Barlow, B. A. 1963. Studies in Australian Loranthaceae IV. Chromsome numbers and their relationships. Proc. Linn. Soc. N. S. W. 88 : 151-160.

- 1964. Classification of the Loranthaceae and Viscaceae. Proc. Linn. Soc. N. S. W. 89: 268-272.

Bentham, G. and Hooker, J. D. 1883. Genera Plantarum. Vol. 3. J. Bot. (London).

Bhaumic, G. H. 1971. Meiotic studies in genus Loranthus. Sci. Cult. 37: 488-492.

Bir, S. S., Gill, B. S. and Bedi, Y. S. 1980. Cytological studies in Loranthus. Nucleus 23: 59-62.

,-- , and -1982 . IOPB chromsome number reports. Taxon 31 (3): 574-598.

Dahlgren, R. 1977. A commentary on a diagrammatic presentation of the angiosperms. Pl. Syst. Evol. Suppl. 1: 253-283.

Danser, B. H. 1929. On the taxonomy and nomenclature of the Loranthaceae of Asia and Australia. Bull. Jard. Bot. Buitenz. 10: 292-373.

- 1933. A new system for the genera of Loranthaceae Loranthoideae, with a nemenclator for the Old World species of the subfamily. Verh. K. Akad. Wet. 29: 1-128.

De Candolle, A. P. 1930, Collection de mémoires pour servir à l'histoire du rang végétal. Sixieme Memoire. Sur la famille Loranthacées. Chez Trenttel et Wurtz, Paris.

Hooker, J. D. 1885. The Flora of British India. V. L. Reeve and Co., London.

Johri, B. M. and Bhatnagar, S. P. 1972. Loranthaceae. Botanical Monograph No. 8. New Delhi, C.S.I.R.

- and Nag, K. K. 1968, Experimental induction of triploid shoots in vitro from endosperm of Dendrophthoe falcata (L.f.) Ettings. Curr. Sci. 37: 606-607.

Kumar, L. S. S. and Abraham, A. 1942. Cytological studies in Indian parasitic plants II. The cytology of Loranthus. Proc. Indian Acad. Sci. 158: 253.

Santapau, H. and Henry, A, N. 1972. A Dictionary of Flowering Plants in India. C.S.I.R., New Delhi.

Schaeppi, H. and Steindl, F. 1942. Blütenmorphologische und embryologische Untersuchungen an Loranthoideen. Vjschr. Natuf. Ges. Zürich 87: 303-372.

Wiens, D. 1964. Chromosome numbers in North American Loranthaceae (Arceuthobium, Phorodendron, Psittacanthus, Struthanthus). Am. J. Bot. 51: 1-6. 